\title{
Characterization of Moisture Diffusion in Cured Concrete Slabs at Early Ages
}

\author{
Xiao Zhang ${ }^{1,2}$ and Hongduo Zhao ${ }^{1}$ \\ ${ }^{1}$ Key Laboratory of Road and Traffic Engineering of the Ministry of Education, Tongji University, Shanghai 201804, China \\ ${ }^{2}$ Key Laboratory of Highway Construction and Maintenance Technology in Loess Region, Shanxi Transportation Research Institute, \\ No. 36 West Xutan Street, Taiyuan, Shanxi 030006, China
}

Correspondence should be addressed to Xiao Zhang; xiaozhang2008@gmail.com

Received 6 January 2015; Accepted 28 April 2015

Academic Editor: Akihiko Kimura

Copyright (C) $2015 \mathrm{X}$. Zhang and H. Zhao. This is an open access article distributed under the Creative Commons Attribution License, which permits unrestricted use, distribution, and reproduction in any medium, provided the original work is properly cited.

\begin{abstract}
The objective of this paper is to investigate the characterization of moisture diffusion inside early-age concrete slabs subjected to curing. Time-dependent relative humidity $(\mathrm{RH})$ distributions of three mixture proportions subjected to three different curing methods (i.e., air curing, water curing, and membrane-forming compounds curing) and sealed condition were measured for 28 days. A one-dimensional nonlinear moisture diffusion partial differential equation (PDE) based on Fick's second law, which incorporates the effect of curing in the Dirichlet boundary condition using a concept of curing factor, is developed to simulate the diffusion process. Model parameters are calibrated by a genetic algorithm (GA). Experimental results show that the RH reducing rate inside concrete under air curing is greater than the rates under membrane-forming compound curing and water curing. It is shown that the effect of water-to-cement $(\mathrm{w} / \mathrm{c})$ ratio on self-desiccation is significant. Lower w/c ratio tends to result in larger $\mathrm{RH}$ reduction. $\mathrm{RH}$ reduction considering both effect of diffusion and self-desiccation in early-age concrete is not sensitive to w/c ratio, but to curing method. Comparison between model simulation and experimental results indicates that the improved model is able to reflect the effect of curing on moisture diffusion in early-age concrete slabs.
\end{abstract}

\section{Introduction}

An understanding of temperature curling and moisture warping gradients in Portland cement concrete (PCC) pavement slabs due to environmental loads plays an important and fundamental role in the process of rigid pavement stress analysis. Temperature gradients and their resulting curling effects on slabs have been well solved and implemented in the pavement engineering community while a sound interpretation of moisture warping which is caused by a nonuniform moisture distribution through the depth of slabs is still lacking [1]. Typically, moisture gradients in concrete pavement generate differential shrinkage between the top and bottom of pavement, which leads to warping stresses. Field investigation shows that the top of pavement is in tension but the bottom is in compression for a vast majority of time [2].

The moisture gradients within an in-service slab depend not only on environmental conditions, such as ambient air relative humidity $(\mathrm{RH})$, solar radiation, temperature, wind speed, and local rainfall, but also on concrete properties, such as water-to-cement (w/c) ratio, cement and aggregates type, and curing method $[3,4]$. Accurate and validated moisture transport modeling in PCC pavement slabs which can properly incorporate all these influencing factors is critical for developing moisture gradients and calculating warping stresses in slabs.

Three primary mechanisms control the moisture transport (namely, water movement) process in concrete, that is, permeation, diffusion, and absorption $[5,6]$. Permeation is the movement of the water flow under a pressure gradient. Diffusion, driven by moisture concentration differential, occurs inside of concrete and absorption, resulting from capillary suction on concrete surface, takes place when concrete is in contact with liquid water. The latter two are major driving forces because concrete pavement slabs are generally neither fully saturated nor subject to a pressure head and therefore permeation can be neglected [6]. The diffusion process of concrete slabs at early ages is the primary focus in this paper. 
The biggest challenge for diffusion modeling is the selection moisture diffusivity function with associated parameters and proper boundary conditions which can properly interpret experimental results. For concrete pavement, curing is one of the important factors affecting the diffusion process in concrete early ages.

The aim of this paper is to determine the modeling parameter that characterizes the diffusion in early-age concrete slabs subjected to different curing methods through laboratory measurements and numerical simulations.

\section{Literature Review}

Extensive studies have been conducted on the characterization and modeling of moisture diffusion of concrete slabs from the prospective of both numerical simulation and laboratory or in situ measurements. In situ investigations have shown that the moisture gradient varies significantly to a depth of approximately $5 \mathrm{~cm}$ (2 inches), whereas the deeper portions of pavement slab remain at approximately $80 \%$ of saturation or higher [7]. Laboratory experimental measurements and simulations showed that the influential depth is about 50 to $100 \mathrm{~mm}$ from the external surface drying [6].

Modeling of moisture diffusion in concrete generally considers the external drying of concrete exposed to atmospheric environment, self-desiccation due to cement hydration, or both. A number of references are found in literatures on the investigation of moisture diffusion due to external drying in concrete. Parrott $[3,4]$ developed an empirical $\mathrm{RH}$ prediction model based on experimental data in which w/c ratio, drying time, and ambient RH are dependent variables. In Persson's empirical model, $\mathrm{RH}$ is formulated as a function of w/c ratio and drying time [8]. Bažant and Najjar [9] firstly developed a nonlinear diffusion equation for concrete in which diffusivity function depends on the moisture content of concrete, porosity of concrete, $w / c$ ratio, and internal temperature distribution. In the partial differential equation (PDE), constant environmental $\mathrm{RH}$ is used in the third-type surface boundary condition. The concept of equivalent thickness $(0.75 \mathrm{~mm})$ is used to describe air curing effect. Akita et al. [10] confirmed the effectiveness of the diffusion equation and reported the values of parameters in diffusivity function for a wide range of concrete mixture proportions. Effect of cement self-desiccation was considered in the modeling of moisture diffusion of concrete at early ages by Kim and Lee [11]. It was reported that low-strength concrete with high w/c ratio was mostly influenced by moisture diffusion due to drying rather than self-desiccation. In high-strength concrete with low w/c ratio, nevertheless, self-desiccation had a substantial influence on moisture development. Similarly, Wong et al. [12] carried out water diffusion tests in concrete at different $\mathrm{w} / \mathrm{c}$ ratios and ambient temperatures. A calibrated S-shaped diffusivity function as proposed by Bažant and Najjar [9] was derived, whose parameters are in good agreement with those reported by Sakata [13] and Hanson [14]. The same model was adopted by Aquino et al. [15] for partial enclosed concrete columns.

Recently, Wei et al. $[1,6]$ measured the time-dependent internal $\mathrm{RH}$ profiles of concrete slabs due to three moisture transport processes, for example, self-desiccation, external drying, and water absorption, which were validated using a numerical simulation procedure considering these three processes simultaneously. In the PDE model, diffusivity function proposed by Bažant and Najjar [9] and the Dirichlet boundary condition were adopted. Zhang et al. [16-18] investigated the development of internal RH of C40 and C80 concrete slabs at early ages by means of both laboratory experiments and numerical calculation. In the process of modeling, both cement hydration and moisture diffusion resulting humidity variations are taken into account synchronously. In the PDE model, a multiple-linear diffusivity function and the Dirichlet boundary condition were used. In the FHWA HIPERPAVE moisture transport model [19], diffusivity function by Bažant and Najjar [9] was adopted. The self-desiccation model developed by Oh and Cha [20] and the third-type surface boundary condition were used in the model. The impact of external factors such as drying and wetting cycles, wind speed, and ambient RH on moisture diffusion was investigated by Qin and Hiller [21]. Except for widely used diffusivity function by Bažant and Najjar [9], some other functions were also proposed in the modeling of moisture diffusion in concrete [22, 23].

A comprehensive survey of the current research efforts suggests that nonlinear diffusion equation, which is also called Fick's second law, is widely accepted for modeling of moisture diffusion for both immature and hardened concrete. There is a lack of systematic and extensive studies on the mechanisms of moisture diffusion in concrete at early ages subjected to different curing methods. The quantification of model parameters characterizing curing is still inadequate due to limited experimental data. The effect of curing on moisture diffusion in concrete slabs still remains unknown.

\section{Experimental Program}

3.1. Materials. Specimens were casted using normal Portland cement, coarse aggregate, and fine aggregate. The class of normal Portland cement is P.O. 42.5; coarse aggregate is crushed limestone with a maximum size of $31.5 \mathrm{~mm}$; fine aggregate is natural sand with a fineness modulus of 2.86 . To get a slump of $80-100 \mathrm{~mm}$, a liquid water-reducing admixture with a dosage (by weight) of $1.0 \%$ is used. The concrete mixture proportions are listed in Table 1. Four specimens were casted for each mixture proportion.

3.2. Moisture Diffusion Tests. To investigate time-dependent moisture distributions in early-age concrete subjected to different curing methods, three methods (e.g., air curing, water curing, and membrane-forming compounds curing) were used in the experiments for three specimens. To simplify the testing and modeling processes, one-dimensional (1D) moisture diffusion in concrete is designed in the one-face drying tests. Waterproof plywood molds with inner surface joints sealed were used to prevent moisture loss from other five faces of specimens. This ensures that moisture can only be evaporated from surface face.

Variations in moisture content, in terms of RH, were measured at two positions within each concrete slab specimen 
TABLE 1: Mixture proportions of concrete $\left(\mathrm{kg} / \mathrm{m}^{3}\right)$.

\begin{tabular}{lcccccc}
\hline Mixture number & w/c & Cement & Water & Sand & $\begin{array}{c}\text { Coarse aggregate } \\
(4.75-9.5 \mathrm{~mm})\end{array}$ & $\begin{array}{c}\text { Coarse aggregate } \\
(9.5-31.5 \mathrm{~mm})\end{array}$ \\
\hline N30 & 0.3 & 390 & 117 & 738 & 462 & 692 \\
N40 & 0.4 & 390 & 156 & 723 & 452 & 678 \\
N50 & 0.5 & 390 & 195 & 707 & 442 & 664 \\
\hline
\end{tabular}

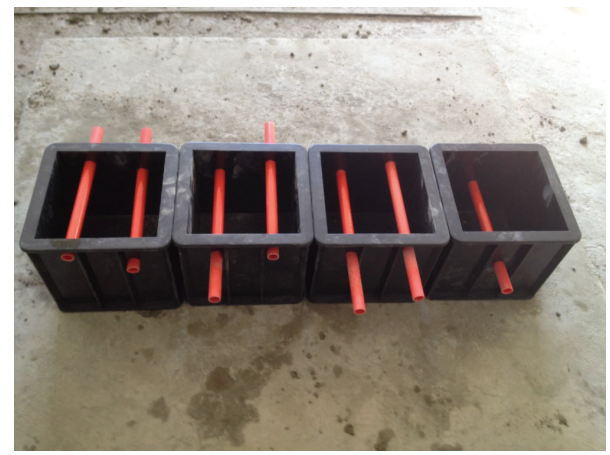

FIgURE 1: Waterproof plastic mold with PVC tubes.

with dimensions of $150 * 150 * 150 \mathrm{~mm}$. Sensirion SHT15 digital humidity and temperature combined sensors were used to measure the humidity and temperature in slabs. The manufacturer-reported accuracies of relative humidity and temperature measurements are $\pm 2 \%$ and $\pm 0.3^{\circ} \mathrm{C}$, respectively. The sensor was calibrated using standard environmental chamber with known RH in the range of $40-100 \%$.

To keep the sensor at the designed location in concrete, two holes with a diameter of $14 \mathrm{~mm}$ were drilled in two opposite faces of a plastic mold and then two PVC tubes with outer diameter of $14 \mathrm{~mm}$ were inserted into those holes prior to casting of concrete, as shown in Figure 1. Tubes were slowly retracted a certain period of time after concrete casting and $\mathrm{RH}$ probes were inserted into the holes in concrete for measurement. The optimal pulling out time may vary for different cement type, casting temperature, and ambient RH. The optimal time was determined to be four hours in the present study based on the results of a series of pretests. The hole-ends were sealed using silicone plugs and paraffin wax. The schematic and real setups of tests are shown in Figures 2 and 3, respectively. Two additional sensors were placed in the surface of specimen to measure the ambient $\mathrm{RH}$ and temperature. An air conditioner was used to control indoor environmental temperatures.

Since self-desiccation exists in cementitious mixtures because cement hydration continues and it causes uniform $\mathrm{RH}$ reduction in concrete and the extent depends on the initial w/c ratio and the degree of hydration [6], $\mathrm{RH}$ reductions caused by cement self-desiccation at different $\mathrm{w} / \mathrm{c}$ ratio levels were also measured for sealed specimens.

Curing was implemented immediately after retracting of PVC tubes. Three different curing methods are applied to three specimens with same mixture proportions. A total of nine diffusion tests were carried out. For water curing, an amount of $0.1 \mathrm{~kg}$ water was sprayed on the drying face

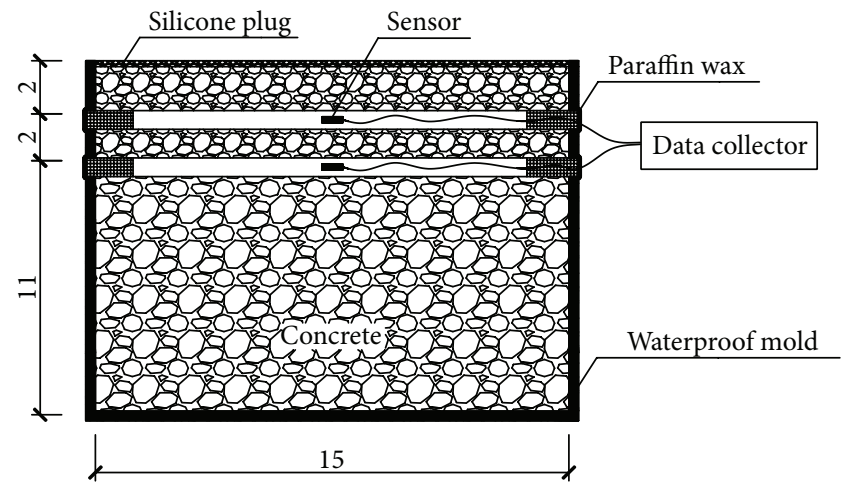

FIGURE 2: Schematic of RH measurement for concrete at different locations (unit: $\mathrm{cm}$ ).

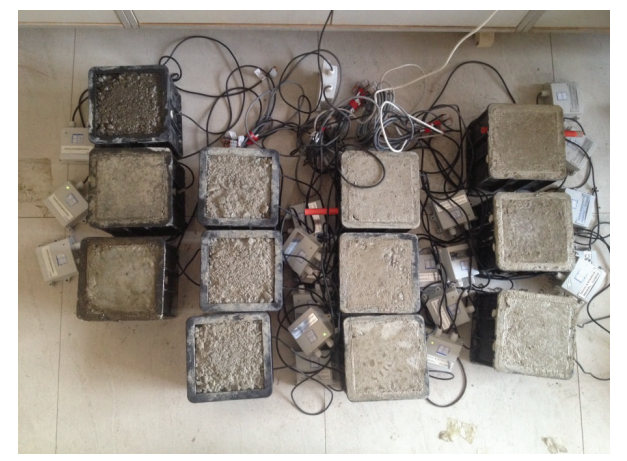

FigURE 3: RH tests for early-age concrete.

of concrete once a day for the entire testing period; for membrane-forming compounds curing, $0.05 \mathrm{~kg}$ liquid curing compound was uniformly sprayed on the surface; for air curing, ambient air is directly applied on the specimen surface.

\section{Model Development and Solution}

4.1. Development of Moisture Diffusion Model. As described in previous literatures, 1D moisture diffusion process in concrete can be described by using Fick's second law as

$$
\frac{\partial\left(\mathrm{RH}-\mathrm{RH}_{L}\right)}{\partial t}=\frac{\partial}{\partial x}\left\{D \cdot \frac{\partial}{\partial x}\left(\mathrm{RH}-\mathrm{RH}_{L}\right)\right\}
$$

where $\mathrm{RH}=$ pore $\mathrm{RH}$ in concrete, $0 \leq \mathrm{RH} \leq 1$; $\mathrm{RH}_{L}=$ pore $\mathrm{RH}$ reduction in concrete resulting from self-desiccation, $0 \leq$ $\mathrm{RH} \leq 1 ; x=$ depth of concrete slabs from top to bottom; 
$t=$ time; and $D=$ diffusivity coefficient $\left(\mathrm{m}^{2} / \mathrm{s}\right)$, which is a function of concrete $\mathrm{RH}$ and is expressed as [9]

$$
D=D_{0}\left(\alpha_{0}+\frac{1-\alpha_{0}}{1+\left((1-\mathrm{RH}) /\left(1-\mathrm{RH}_{\partial}\right)\right)^{n}}\right),
$$

where $D_{0}=$ maximum of $D$ at full saturation; namely, $\mathrm{RH}=100 \% ; \alpha_{0}=$ ratio of minimum to maximum diffusivity coefficient; $\mathrm{RH}_{\partial}=$ concrete $\mathrm{RH}$ at $D=0.5 D_{0}$; and $n$ $=$ parameter that characterizes the spread of the drop in diffusion coefficient.

4.2. Self-Desiccation Model. Humidity reduction, also called moisture sink, results from the chemical reaction between cement and water and is dependent on cement hydration degree. The model proposed by $\mathrm{Oh}$ and Cha [20] is adopted in this paper to characterize the moisture loss due to selfdesiccation, which is expressed as

$$
\mathrm{RH}_{s}=\left(\mathrm{RH}_{s, u}-1\right)\left(\frac{\alpha}{\alpha_{u}}\right)^{S}+1,
$$

where $\mathrm{RH}_{s}=\mathrm{RH}$ in concrete resulting from self-desiccation; $\alpha_{u}=$ ultimate degree of hydration; $\alpha=$ degree of hydration; $\mathrm{RH}_{s, u}=\mathrm{RH}$ due to self-desiccation at ultimate degree of hydration; and $S=$ parameter that depends on $\mathrm{w} / \mathrm{c}$ ratio.

Therefore, $\mathrm{RH}$ reduction $\mathrm{RH}_{L}$ can be rewritten as follows:

$$
\mathrm{RH}_{L}=1-\mathrm{RH}_{s}=-\left(\mathrm{RH}_{s, u}-1\right)\left(\frac{\alpha}{\alpha_{u}}\right)^{S} .
$$

Exponential concrete hydration model proposed by Pane and Hansen [24] is adopted to capture the relationship between degree of hydration and equivalent age, which is defined as

$$
\alpha=\alpha_{u} e^{-\left(\tau / t_{e}\right)^{\beta}},
$$

where ultimate degree hydration $\alpha_{u}$ is expressed as in the following equation proposed by Mills [25]:

$$
\alpha_{u}=\frac{1.031 \mathrm{w} / \mathrm{c}}{0.194+\mathrm{w} / \mathrm{c}} ;
$$

$\tau=$ hydration time parameter $(\mathrm{h}) ; \beta=$ hydration shape parameter; and $t_{e}=$ equivalent age at reference temperature $\left(21.1^{\circ} \mathrm{C}\right), \mathrm{h}$.

Arrhenius method is used to represent the equivalent age of concrete at the reference temperature that would result in the same value of maturity as the curing period for the given average temperature, which is expressed as [26]

$$
t_{e}=\sum \exp \left\{-\frac{E}{R}\left[\left(\frac{1}{273+T_{a}}\right)-\left(\frac{1}{273+T_{r}}\right)\right]\right\} \Delta t,
$$

where $E=$ activation energy, $\mathrm{J} / \mathrm{mol}=\{33,500, T \geq$ $\left.20^{\circ} \mathrm{C} ; 33,500+1472(20-T), T<20^{\circ} \mathrm{C}\right\}, R=$ universal gas constant, $8.3144 \mathrm{~J} /(\mathrm{mol} \mathrm{K}), T_{a}=$ average concrete temperature during time interval $\Delta t,{ }^{\circ} \mathrm{C} ; T_{r}=$ reference temperature, $21.1^{\circ} \mathrm{C}$; and $\Delta t=$ time interval.
4.3. Initial and Boundary Conditions considering Curing Effect. Since concrete is fully saturated right after casting, initial condition for governing equation (1) is as follows:

$$
\mathrm{RH}(x, t)=100 \%, \quad t=0 .
$$

With respect to top boundary condition (drying surface condition), most of current studies use either the Dirichlet or the third-type boundary condition, which are shown as follows, respectively:

$$
\begin{aligned}
& \mathrm{RH}(x, t)=\mathrm{RH}_{e n}, \quad x=0, t>0, \\
& -D \frac{\partial \mathrm{RH}}{\partial x}=f \cdot\left(\mathrm{RH}_{s}-\mathrm{RH}_{e n}\right), \quad x=0, t>0,
\end{aligned}
$$

where $\mathrm{RH}_{s}=\mathrm{RH}$ at drying surface; $\mathrm{RH}_{e n}=\mathrm{RH}$ of ambient air; and $f=$ surface factor.

It is shown that $\mathrm{RH}$ of slab at $x=0$ directly equals $\mathrm{RH}$ of ambient air in the Dirichlet boundary condition, which means that there exists no moisture gradient in the interface of slab and air. A recent experiment by Li [27] shows that the moisture gradient in the interface of slab and air gradually reduces and disappears. Therefore, it is recommended to use the Dirichlet boundary condition in the external drying modeling of concrete instead of the third-type boundary condition [27].

For the third-type boundary condition, it is physically reasonable because it demonstrates the mechanism of moisture exchange between ambient air and concrete in the slab surface. However, it is particularly difficult to quantify surface factor as it is dependent on a few factors, such as concrete surface texture, w/c ratio, wind speed, and temperature. Since it cannot be directly measured by experimental methods, current knowledge on surface factor is only based on statistical regression from limited experimental data [10]. Accordingly, the third-type boundary condition is not used in the present paper.

Curing of concrete with water or membrane basically changes the top boundary condition because the essence of curing is to cover with a layer of water or chemical compound the concrete surface for a predetermined period of time, which prevents excessive loss of moisture compared with air curing. For membrane-forming compound curing and water curing, a certain thick of concrete surface is initially subjected to unsaturated or saturated condition. Moisture decreases gradually as drying time goes. The average moisture content of concrete surface during this period is greater than the moisture content compared with the situation of air curing. Therefore, the effect of curing can be mathematically treated as a modification of the Dirichlet condition in the modeling of moisture diffusion. Combining with the results by Li [27], this present paper introduces a concept of curing factor to account for this effect for the top boundary condition in the diffusion model. Accordingly, (9) can be rewritten as

$$
\mathrm{RH}(x, t)= \begin{cases}f_{c} \mathrm{RH}_{e n}, & \text { if } f_{c} \mathrm{RH}_{e n}<1, x=0, t>0, \\ 1, & \text { if } f_{c} \mathrm{RH}_{e n} \geq 1, x=0, t>0,\end{cases}
$$

where $f_{c}$ is curing factor to be calibrated and it is equal to 1 for case of air curing. 


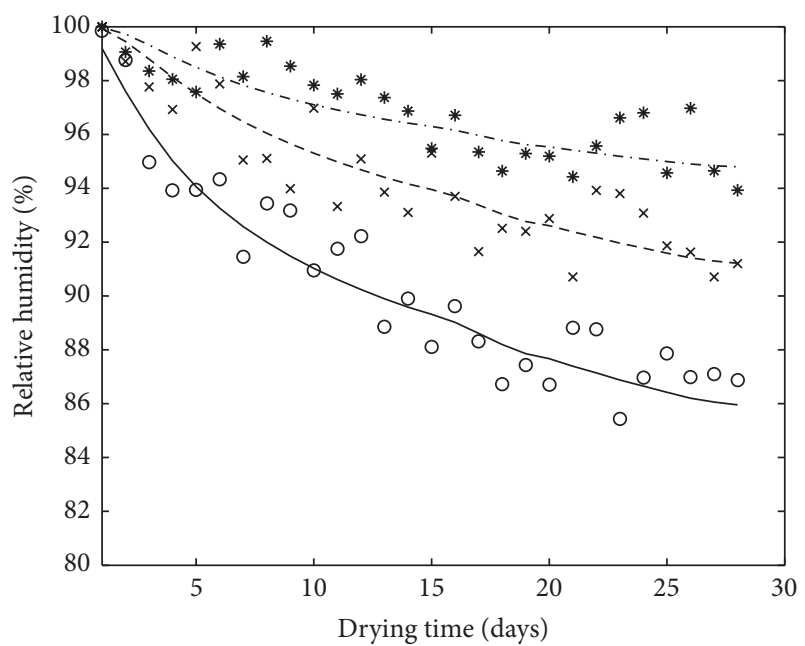

— Simulated results for N30 。 Tested results for N30

- - - Simulated results for N40 $\times$ Tested results for N40

..- Simulated results for N50 * Tested results for N50

FIGURE 4: RH due to self-desiccation.

With respect to bottom boundary condition, since the specimen is sealed, Neumann boundary condition is used as in

$$
\frac{\partial \mathrm{RH}}{\partial x}=0, \quad x=l, t>0
$$

where $l$ is the height of specimen.

4.4. Model Solution. The Crank-Nicolson scheme which is an implicit finite difference method is used to numerically solve the developed diffusion model, as shown in (1), with initial condition (8) and boundary conditions (11) and (12).

Let $\mathrm{RH}_{i, j}$ denote the $\mathrm{RH}$ of $i$ th node at $j$ th time step. $\Delta x$ and $\Delta t$ represent location step length and time step length. The Crank-Nicolson scheme for an internal node is

$$
\begin{aligned}
-D_{j-1 / 2} \mathrm{RH}_{i+1, j-1} & \\
& +\left(\frac{2(\Delta x)^{2}}{\Delta t}+D_{j+1 / 2}+D_{j-1 / 2}\right) \mathrm{RH}_{i+1, j} \\
& -D_{j+1 / 2} \mathrm{RH}_{i+1, j+1} \\
= & D_{j-1 / 2} \mathrm{RH}_{i, j-1} \\
& +\left(\frac{2(\Delta x)^{2}}{\Delta t}-D_{j+1 / 2}-D_{j-1 / 2}\right) \mathrm{RH}_{i, j} \\
& -D_{j+1 / 2} \mathrm{RH}_{i, j+1} .
\end{aligned}
$$

For the surface node, the ambient air $\mathrm{RH}$ is directly applied. Time-dependent ambient air RH is used in this study. It is noteworthy that almost all existing studies adopted a constant value of the ambient air RH. The finite difference form for surface node is given by

$$
\mathrm{RH}_{1, j}= \begin{cases}f_{c} \mathrm{RH}_{e n}(j), & \text { if } f_{c} \mathrm{RH}_{e n}(j)<1, \\ 1, & \text { if } f_{c} \mathrm{RH}_{e n}(j) \geq 1 .\end{cases}
$$

TABLE 2: Major parameter values of GA.

\begin{tabular}{lc}
\hline Parameters & Value/range \\
\hline Chromosomes crossover type & Blending \\
Chromosomes mutation type & Random \\
Maximum generation & 500 \\
Population size & 100 \\
Random seed & 6 \\
Crossover probability & 0.95 \\
$\mathrm{RH}_{s, u}$ & {$[0.70,0.98]$} \\
$S$ & {$[3,5]$} \\
$\tau$ & {$[1,60]$} \\
$\beta$ & {$[0,1]$} \\
$D_{0}\left(\times 10^{-10} \mathrm{~m}^{2} / \mathrm{s}\right)$ & {$[0.1,8.0]$} \\
$\alpha_{0}$ & {$[0.01,0.1]$} \\
$\mathrm{RH}_{\partial}$ & {$[0.6,0.98]$} \\
$n$ & {$[1,16]$} \\
$f_{c}$ & {$[1,3]$} \\
\hline
\end{tabular}

For the slab bottom node, $\mathrm{RH}$ of $(N+1)$ th node is equal to that of $N$ th node, which is expressed as

$$
\mathrm{RH}_{N+1, j}=\mathrm{RH}_{N, j} \text {. }
$$

4.5. Calibration of Model Parameters. To determine the parameters in models of diffusion and self-desiccation model, a standard genetic algorithm (GA) calibration procedure is used [28]. The logic of the calibration is to find the optimal value of parameters which can minimize the difference between simulated $\mathrm{RH}$ and measure $\mathrm{RH}$ of concrete for both diffusion and self-desiccation models. The Root Mean Square Error (RMSE) is used as fitness function in GA, which is defined by

$$
\mathrm{RMSE}=\sqrt{\frac{\sum_{w=1}^{a} \sum_{k=1}^{b}\left(\mathrm{RH}_{k, w}^{\text {mea }}-\mathrm{RH}_{k, w}^{\text {sim }}\right)^{2}}{a b}},
$$

where $\mathrm{RH}_{k, w}^{\text {mea }}=$ measured concrete $\mathrm{RH}$ at $w$ th location when drying time index is $k$; $\mathrm{RH}_{k, w}^{\text {sim }}=$ simulated concrete $\mathrm{RH}$ at $w$ th location when drying time index is $k ; w=\mathrm{RH}$ sensor location index, $w=1$ for self-desiccation model and $w=1,2$ for diffusion model; $a=$ number of sensors, $a=2$; and $k=$ drying time index in simulation and measurement, $k=1,2, \ldots, b$.

A MATLAB program for performing GA is developed in this study. The major GA parameter values used in this study are based on the survey of literatures $[5,9,10,12,16,19,20]$ and are illustrated in Table 2.

\section{Results and Discussions}

5.1. Comparison of Tests with Model Simulation Results. Moisture diffusion tests for three specimens for each mixture's proportions subjected to three different curing methods were conducted for 28 days. $\mathrm{RH}$ reductions caused by cement self-desiccation at three $\mathrm{w} / \mathrm{c}$ ratios were also measured for three sealed specimens. $\mathrm{RH}$ data were measured every $1 \mathrm{~h}$ and averaged in a $24 \mathrm{~h}$ interval at the data processing stage. 


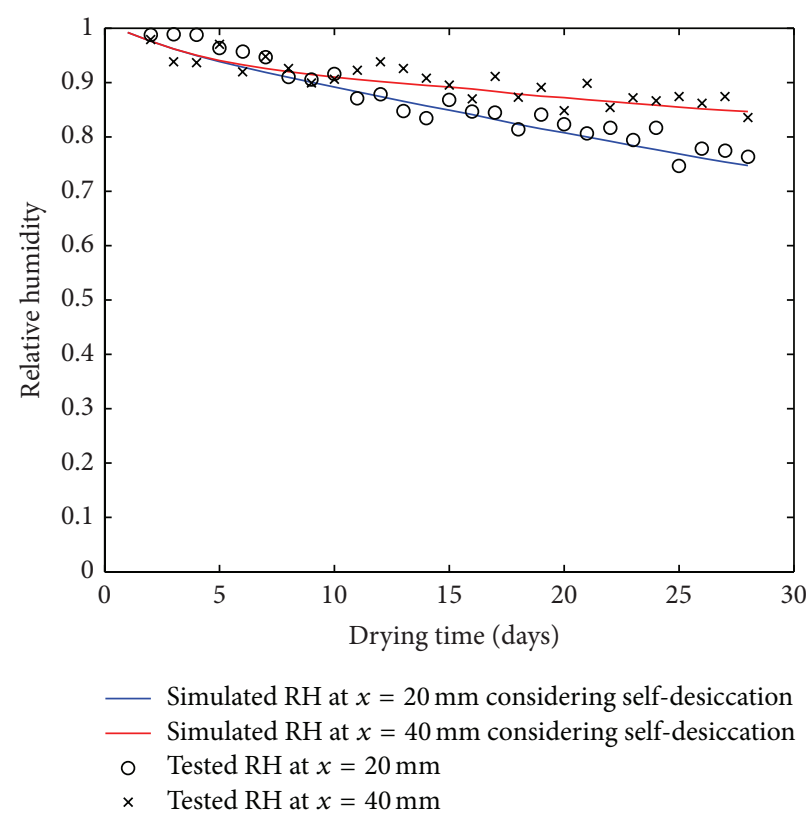

(a)

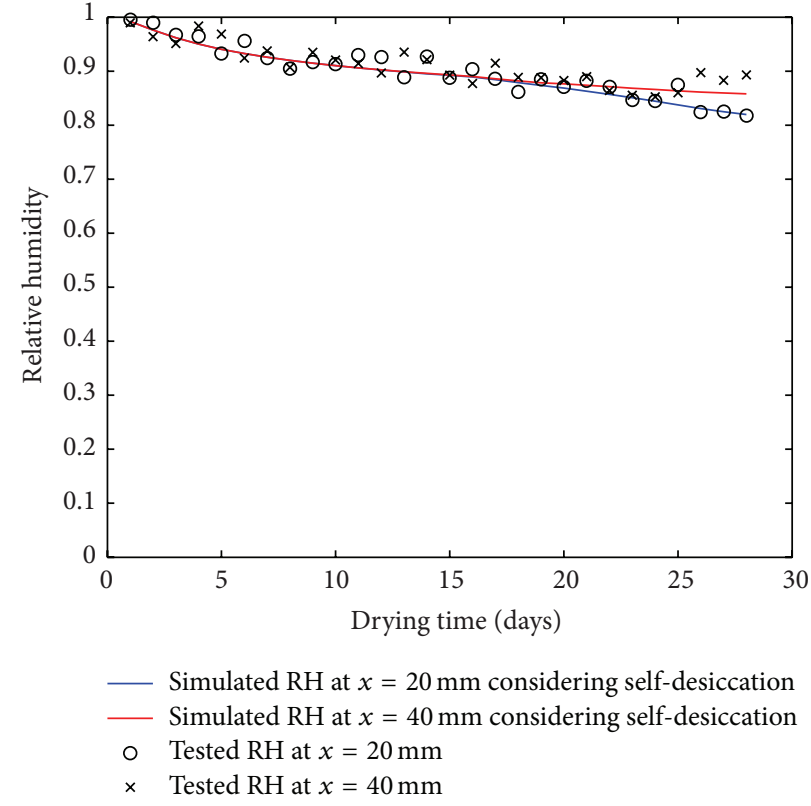

(b)
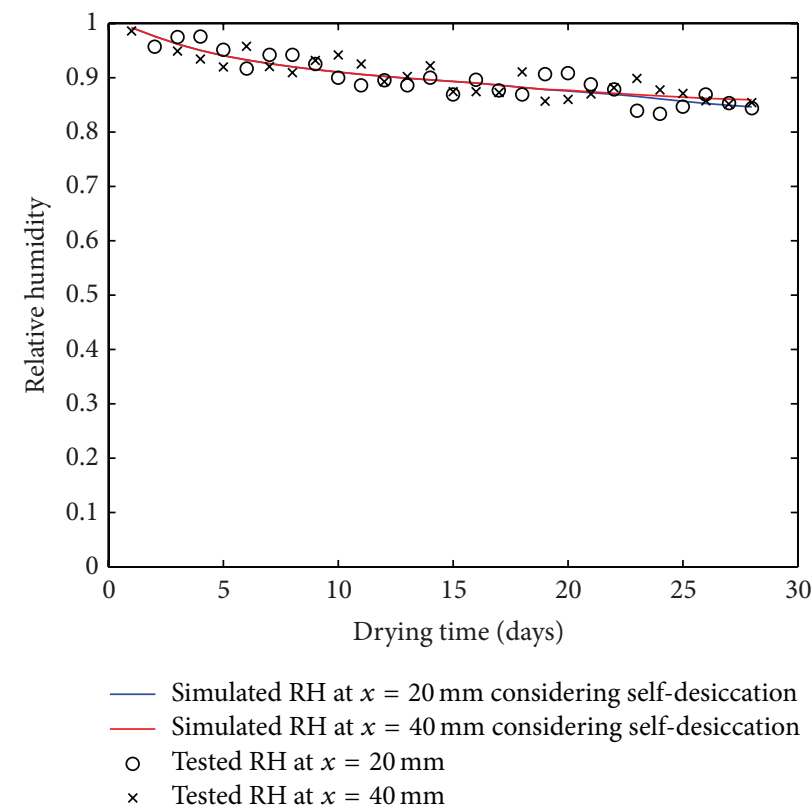

(c)

Figure 5: Comparisons of test results with model simulations for N30: (a) air curing, (b) membrane-forming compound curing, and (c) water curing.

TABLE 3: Calibrated parameters for self-desiccation model.

\begin{tabular}{lccccc}
\hline Mixture number & $\mathrm{RH}_{s, u}$ & $\alpha_{u}$ & $S$ & $\tau$ & $\beta$ \\
\hline N30 & 0.80 & 0.626 & 4.64 & 15 & 0.62 \\
N40 & 0.87 & 0.694 & 4.12 & 38 & 0.76 \\
N50 & 0.93 & 0.743 & 3.48 & 50 & 0.81 \\
\hline
\end{tabular}

The calibrated parameters for diffusion and self-desiccation models are presented in Tables 3 and 4 . For curing factor, it describes the quality of curing effect. Large value of curing factor means the curing is more effective for preventing water evaporation from concrete surface. The physical meanings of the other calibrated parameters are described previously in Sections 4.1 and 4.2. Figure 4 illustrates the predicted and measured $\mathrm{RH}$ distributions due to self-desiccation of concrete for mixture proportions N30, N40, and N50. The measured and simulated variations of $\mathrm{RH}$ at the distances of 20 and $40 \mathrm{~mm}$ from exposed surface due to both moisture diffusion and self-desiccation for specimens made by mixture proportions N30, N40, and N50 under three different curing methods are shown in Figures 5, 6, and 7. 


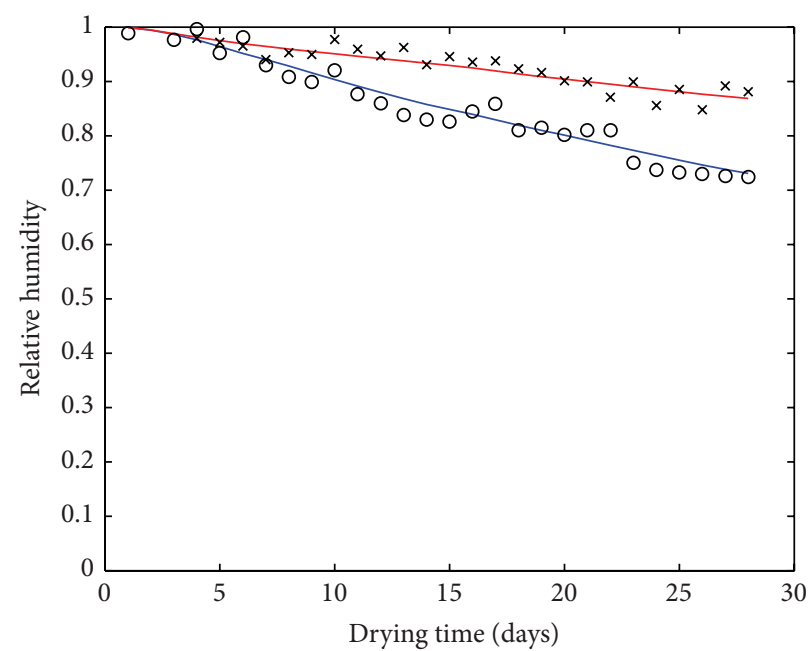

- Simulated RH at $x=20 \mathrm{~mm}$ considering self-desiccation
- Simulated RH at $x=40 \mathrm{~mm}$ considering self-desiccation
○ Tested RH at $x=20 \mathrm{~mm}$
$\times \quad$ Tested RH at $x=40 \mathrm{~mm}$

(a)

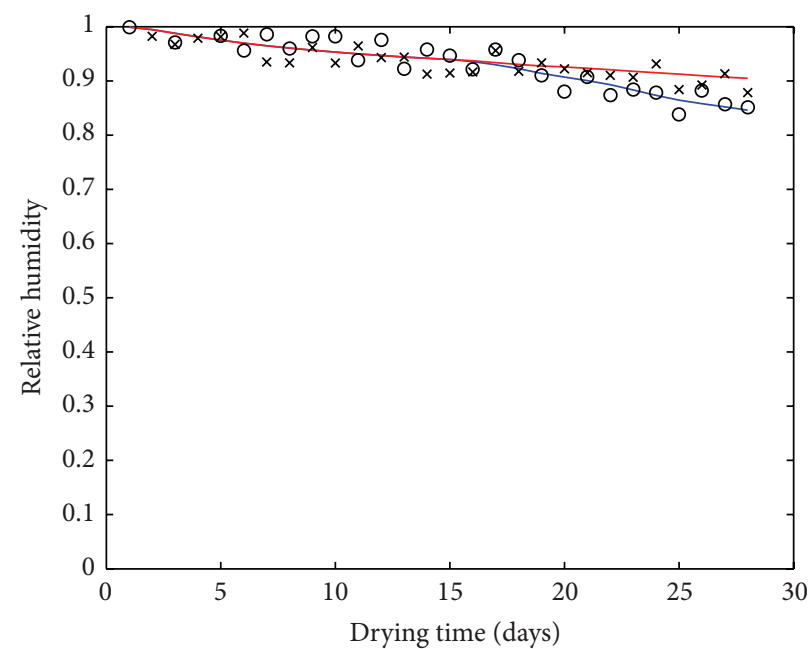

- Simulated RH at $x=20 \mathrm{~mm}$ considering self-desiccation

- Simulated RH at $x=40 \mathrm{~mm}$ considering self-desiccation

○ Tested RH at $x=20 \mathrm{~mm}$

$\times \quad$ Tested RH at $x=40 \mathrm{~mm}$

(b)

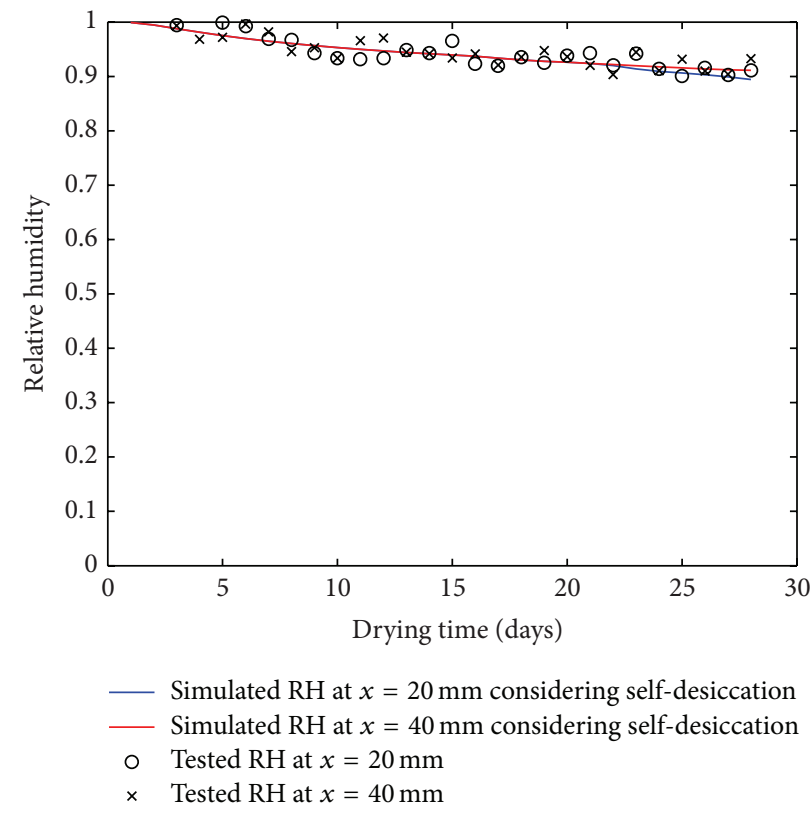

(c)

Figure 6: Comparisons of test results with model simulations for N40: (a) air curing, (b) membrane-forming compound curing, and (c) water curing.

TABLE 4: Calibrated parameters for diffusion model simulation.

\begin{tabular}{lcccccc}
\hline Mixture number & $D_{0}\left(\times 10^{-10} \mathrm{~m}^{2} / \mathrm{s}\right)$ & $\alpha_{0}$ & $\mathrm{RH}_{\partial}$ & $n$ & Air curing & $\begin{array}{c}f_{c} \\
\text { Compound curing }\end{array}$ Water cuing \\
\hline N30 & 0.93 & 0.018 & 0.793 & 1.0 & 1.0 & 2.06 \\
N40 & 1.62 & 0.022 & 0.792 & 1.5 & 1.0 & 2.28 \\
N50 & 2.13 & 0.04 & 0.795 & 2.0 & 1.0 & 2.33 \\
\hline
\end{tabular}




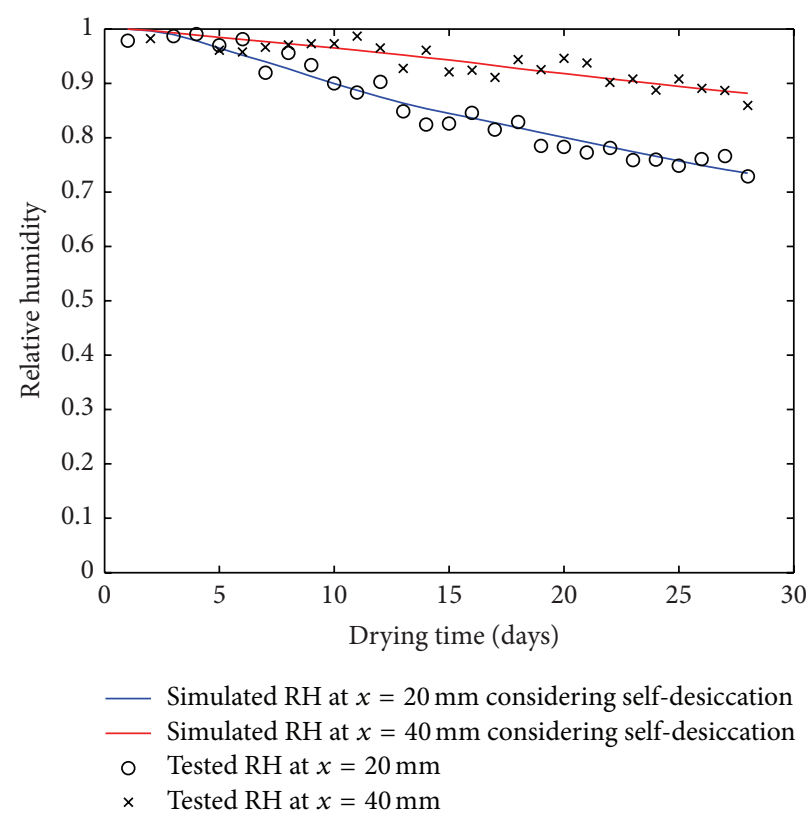

(a)

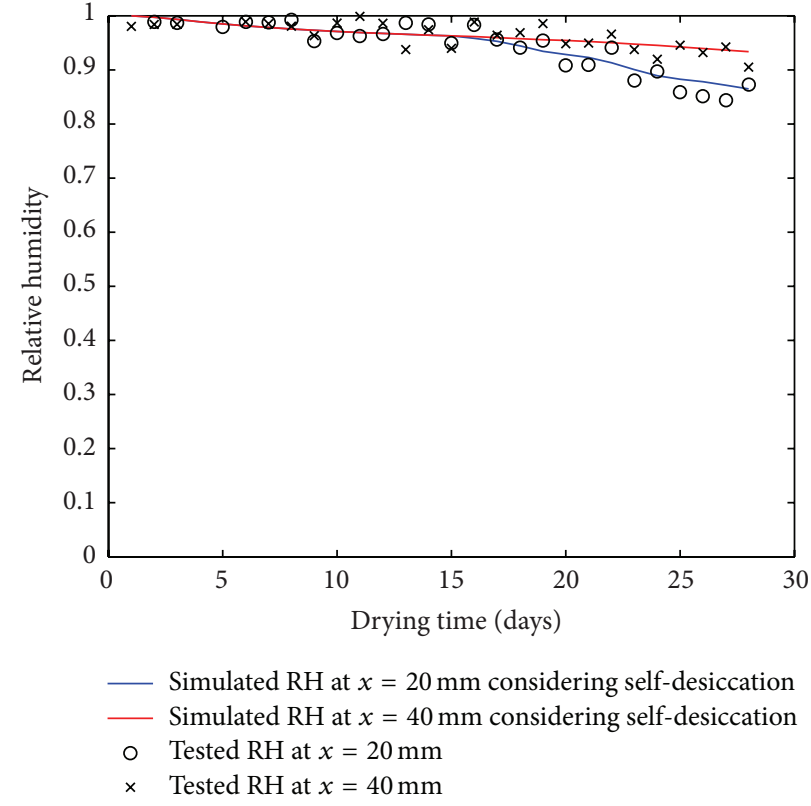

(b)
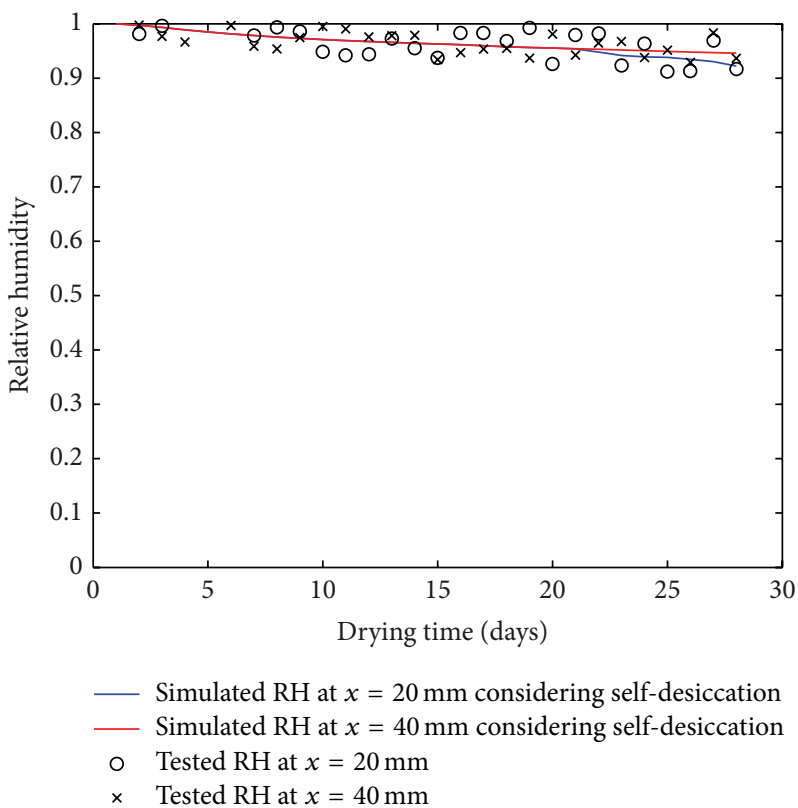

(c)

FIGURE 7: Comparisons of test results with model simulations for N50: (a) air curing, (b) membrane-forming compound curing, and (c) water curing.

It is found from Figure 4 that the $\mathrm{RH}$ due to selfdesiccation after 28 days is around $85 \%, 90 \%$, and $95 \%$ for concrete with $\mathrm{w} / \mathrm{c}$ ratio of $0.3,0.4$, and 0.5 , respectively. This shows that the effect of $w / c$ ratio on self-desiccation is pretty significant. Lower $\mathrm{w} / \mathrm{c}$ ratio tends to result in larger $\mathrm{RH}$ reduction. This result is consistent with previous studies $[11,29,30]$.

It is shown from Figures 5, 6, and 7 that $\mathrm{RH}$ of all specimens at location $x=20$ and $40 \mathrm{~mm}$ gradually decreases due to external drying. However, the reducing rates vary for different curing methods. The overall magnitude of $\mathrm{RH}$ reducing rate is air curing greater than that of both membrane-forming compound curing and water curing for mixtures N30, N40, and N50. For each curing method, however, the final $\mathrm{RHs}$ at two locations after 28 days are almost the same for mixtures N30, N40, and N50. It is therefore concluded that $\mathrm{RH}$ reduction considering both effect of diffusion and self-desiccation in early-age concrete is not sensitive to w/c ratio, but to curing method. Another indication from simulation results is that $\mathrm{RH}$ reducing rates 
at location $x=20$ and $40 \mathrm{~mm}$ are the same for the first several days under the condition of membrane-forming compound curing and water curing (around $17 \mathrm{~d}$ for membrane-forming compound curing and $23 \mathrm{~d}$ for water curing). It is demonstrated that both water and membrane-forming compound curing can prevent the excessive moisture loss of concrete.

5.2. Discussions. With developed moisture diffusion model and experimental results, it is shown that incorporating curing factor in modeling moisture diffusion inside earlyage concrete subjected to curing can result in more accurate simulation results. This is not surprising since concrete curing basically changes the concrete surface moisture content and the curing factor that modifies the boundary condition in the modeling essentially describes the mechanism of curing. Moreover, the use of the Dirichlet boundary condition at the top surface of concrete in the moisture diffusion modeling can avoid the calibration of surface factor in the third-type boundary condition without loss of accuracy. It is therefore concluded that the proposed modified Dirichlet boundary condition is appropriate for the modeling of moisture diffusion in cured concrete at early ages.

The developed approach can produce a reasonable result for the studied concrete mixture. However, a deep exploration of curing factor needs more moisture diffusion experiments and simulations for a variety of concrete with different mixture proportions. Another limitation is that the accuracy of $\mathrm{RH}$ sensor is $\pm 2 \%$, which makes the results interpretation difficult. High-accurate RH sensor is suggested to be used in the future study.

\section{Conclusions}

This paper investigates the characterization of moisture diffusion in early-age concrete slabs subjected to different curing methods using the approach of both theoretical modeling and experimental testing. The moisture development of concrete specimens at three $\mathrm{w} / \mathrm{c}$ ratios subjected to three different curing methods, for example, air curing, water curing, and membrane-forming compounds curing, was experimentally measured for a period of 28 days. Besides, $\mathrm{RH}$ changes over time were measured for sealed specimens at three $\mathrm{w} / \mathrm{c}$ ratios. A one-dimensional nonlinear moisture diffusion partial differential equation (PDE) based on Fick's second law, which incorporates the effect of curing in the boundary condition using a concept of curing factor, is developed to simulate the diffusion process.

Experimental results show that the RH reducing rate inside concrete for three curing methods is air curing greater than membrane-forming compound curing and water curing. It is shown that the effect of $\mathrm{w} / \mathrm{c}$ ratio on self-desiccation is significant. Lower w/c ratio tends to result in larger $\mathrm{RH}$ reduction. Besides, $\mathrm{RH}$ reduction considering both effect of diffusion and self-desiccation in early-age concrete is not sensitive to $\mathrm{w} / \mathrm{c}$ ratio, but to curing method.

It can be concluded that the proposed modified Dirichlet boundary condition in diffusion model is appropriate for the modeling of moisture diffusion in cured concrete at early ages. It is worth noting that the results in the study are based on limited experimental data sets. More tests need to be carried out in the future to draw reliable results for a variety of concrete with different mixture proportions.

\section{Conflict of Interests}

The authors declare that there is no conflict of interests regarding the publication of this paper.

\section{Acknowledgment}

The authors acknowledge that this paper was supported by the National Science Foundation of China, Grant no. 51308329.

\section{References}

[1] Y. Wei and W. Hansen, "Characterization of moisture transport and its effect on deformations in jointed plain concrete pavement," Transportation Research Record, no. 2240, pp. 9-15, 2011.

[2] D. J. Janssen, "Moisture in Portland cement concrete," in Transportation Research Record 1121, pp. 40-44, TRB, National Research Council, Washington, DC, USA, 1987.

[3] L. J. Parrott, "Factors influencing relative humidity in concrete," Magazine of Concrete Research, vol. 43, no. 154, pp. 45-52, 1991.

[4] L. J. Parrott, "Moisture profiles in drying concrete," Advances in Cement Research, vol. 1, no. 3, pp. 164-170, 1988.

[5] R. Henkensiefken, J. Castro, D. Bentz, T. Nantung, and J. Weiss, "Water absorption in internally cured mortar made with waterfilled lightweight aggregate," Cement and Concrete Research, vol. 39, no. 10, pp. 883-892, 2009.

[6] Y. Wei, X. Gao, and W. Hansen, "Influential depth by water absorption and surface drying in concrete slabs," Transportation Research Record, no. 2342, pp. 76-82, 2013.

[7] J. R. Philip and D. A. de Vries, "Moisture movement in porous materials under temperature gradients," Transactions, American Geophysical Union, vol. 38, no. 2, pp. 222-232, 1957.

[8] B. Persson, "Moisture in concrete subjected to different kinds of curing," Materials and Structures, vol. 30, no. 203, pp. 533-544, 1997.

[9] Z. P. Bažant and L. J. Najjar, "Nonlinear water diffusion in nonsaturated concrete," Material and Construction, vol. 5, no. 1, pp. 3-20, 1972.

[10] H. Akita, T. Fujiwara, and Y. Ozaka, "A practical procedure for the analysis of moisture transfer within concrete due to drying," Magazine of Concrete Research, vol. 49, no. 179, pp. 129-137, 1997.

[11] J.-K. Kim and C.-S. Lee, "Moisture diffusion of concrete considering self-desiccation at early ages," Cement and Concrete Research, vol. 29, no. 12, pp. 1921-1927, 1999.

[12] S. F. Wong, T. H. Wee, S. Swaddiwudhipong, and S. L. Lee, "Study of water movement in concrete," Magazine of Concrete Research, vol. 53, no. 3, pp. 205-220, 2001.

[13] K. Sakata, "A study on moisture diffusion in drying and drying shrinkage of concrete," Cement and Concrete Research, vol. 13, no. 2, pp. 216-224, 1983.

[14] J. A. Hanson, "Effects of curing and drying environments on splitting tensile strength," ACI Journal, vol. 65, pp. 535-543, 1968.

[15] W. Aquino, N. M. Hawkins, and D. A. Lange, "Moisture distribution in partially enclosed concrete," ACI Materials Journal, vol. 101, no. 4, pp. 259-265, 2004. 
[16] J. Zhang, K. Qi, and Y. Huang, "Calculation of moisture distribution in early-age concrete," Journal of Engineering Mechanics, vol. 135, no. 8, pp. 871-880, 2009.

[17] J. Zhang, Y. Gao, and Y. Han, "Interior humidity of concrete under dry-wet cycles," Journal of Materials in Civil Engineering, vol. 24, no. 3, pp. 289-298, 2012.

[18] J. Zhang, Y. Huang, K. Qi, and Y. Gao, "Interior relative humidity of normal- and high-strength concrete at early age," Journal of Materials in Civil Engineering, vol. 24, no. 6, pp. 615622, 2012.

[19] Q. Xu, J. M. Ruiz, G. K. Chang et al., "Moisture transport model for enhancing FHWA HIPERPAV predictions," in Transportation Research Record: Journal of the Transportation Research Board 2113, pp. 1-12, Transportation Research Board of the National Academies, Washington, DC, USA, 2009.

[20] B. H. Oh and S. W. Cha, "Nonlinear analysis of temperature and moisture distributions in early-age concrete structures based on degree of hydration," ACI Materials Journal, vol. 100, no. 5, pp. 361-370, 2003.

[21] Y. Qin and J. E. Hiller, "Simulating moisture distribution within concrete pavement slabs: model development and sensitivity study," Materials and Structures, vol. 47, no. 1-2, pp. 351-365, 2014.

[22] H. Garbalińska, S. J. Kowalski, and M. Staszak, "Moisture transfer between unsaturated cement mortar and ambient air," Transport in Porous Media, vol. 85, no. 1, pp. 79-96, 2010.

[23] S.-T. Kang, J.-S. Kim, Y. Lee, Y.-D. Park, and J.-K. Kim, "Moisture diffusivity of early age concrete considering temperature and porosity," KSCE Journal of Civil Engineering, vol. 16, no. 1, pp. 179-188, 2012.

[24] I. Pane and W. Hansen, "Concrete hydration and mechanical properties under nonisothermal conditions," ACI Materials Journal, vol. 99, no. 6, pp. 534-542, 2002.

[25] R. H. Mills, "Factors influencing cessation of hydration in water cured cement pastes. Special report no. 90," in Proceedings of the Symposium on the Structure of Portland Cement Paste and Concrete, pp. 406-424, Highway Research Board, Washington, DC, USA, 1966.

[26] USDOT-FHWA, Maturity Testing for Concrete Pavement Applications, US Department of Transportation, Federal Highway Administration, 2014, http://www.fhwa.dot.gov/pavement/ pccp/pubs/06004/.

[27] C. Li, Study on water and ionic transport processes in cover concrete under drying-wetting cycles [Ph.D. thesis], Tsinghua University, Beijing, China, 2009.

[28] K. Deb, A. Pratap, S. Agarwal, and T. A. M. T. Meyarivan, "A fast and elitist multiobjective genetic algorithm: NSGA-II," IEEE Transactions on Evolutionary Computation, vol. 6, no. 2, pp. 182197, 2002.

[29] Z. Jiang, Z. Sun, and P. Wang, "Internal relative humidity distribution in high-performance cement paste due to moisture diffusion and self-desiccation," Cement and Concrete Research, vol. 36, no. 2, pp. 320-325, 2006.

[30] R. Henkensiefken, D. Bentz, T. Nantung, and J. Weiss, "Volume change and cracking in internally cured mixtures made with saturated lightweight aggregate under sealed and unsealed conditions," Cement and Concrete Composites, vol. 31, no. 7, pp. 427-437, 2009. 

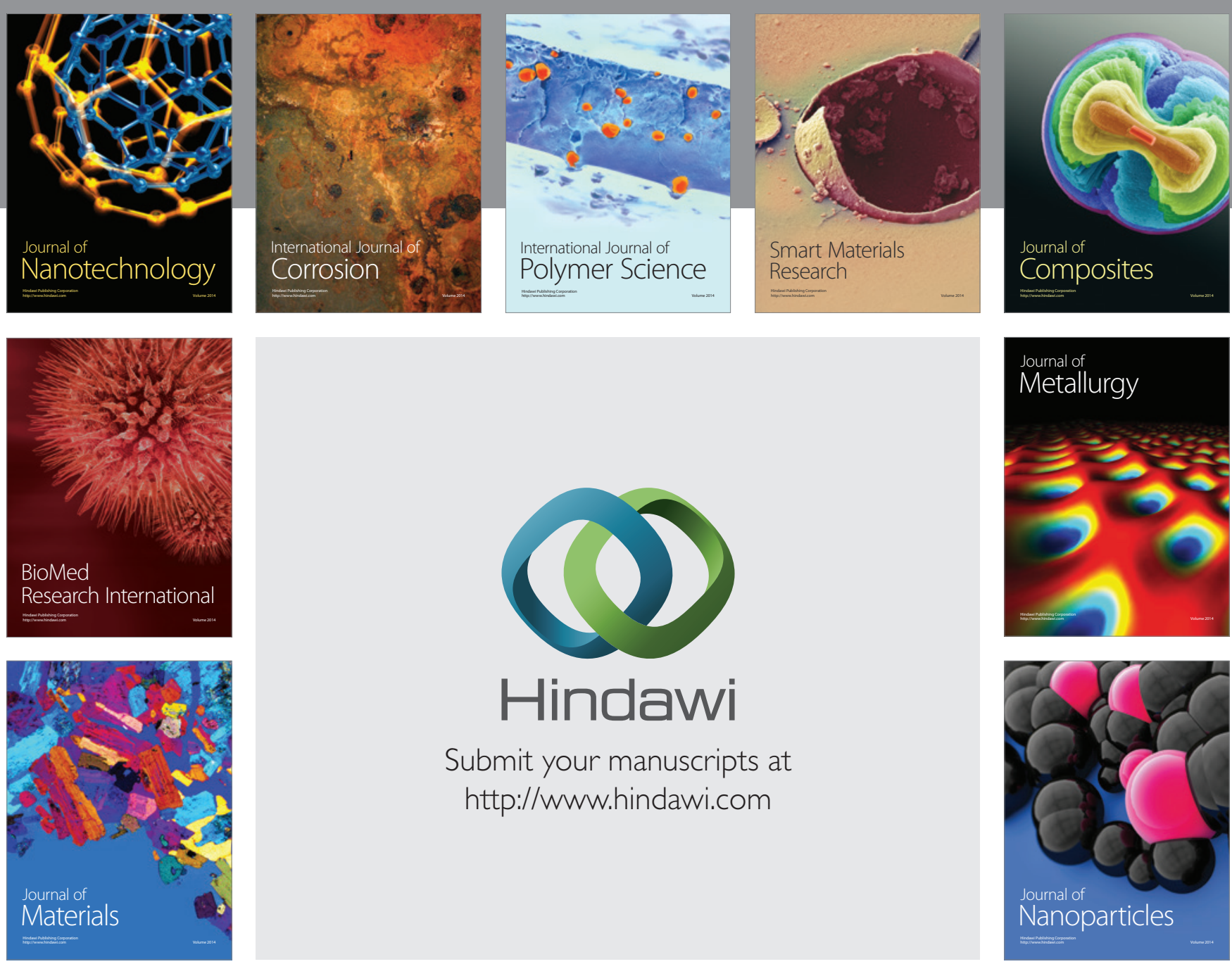

Submit your manuscripts at http://www.hindawi.com
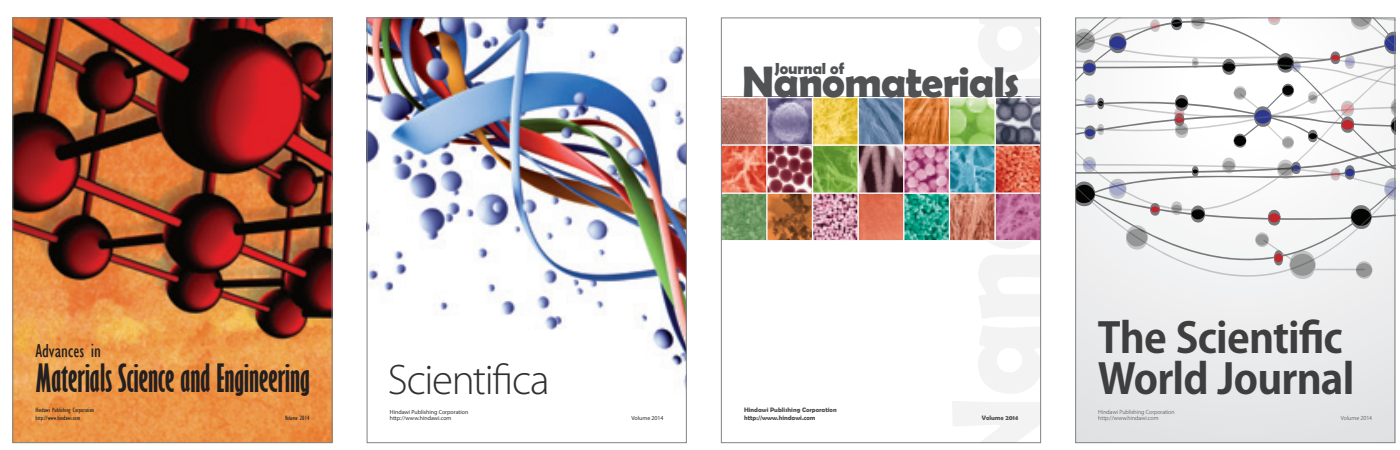

\section{The Scientific World Journal}
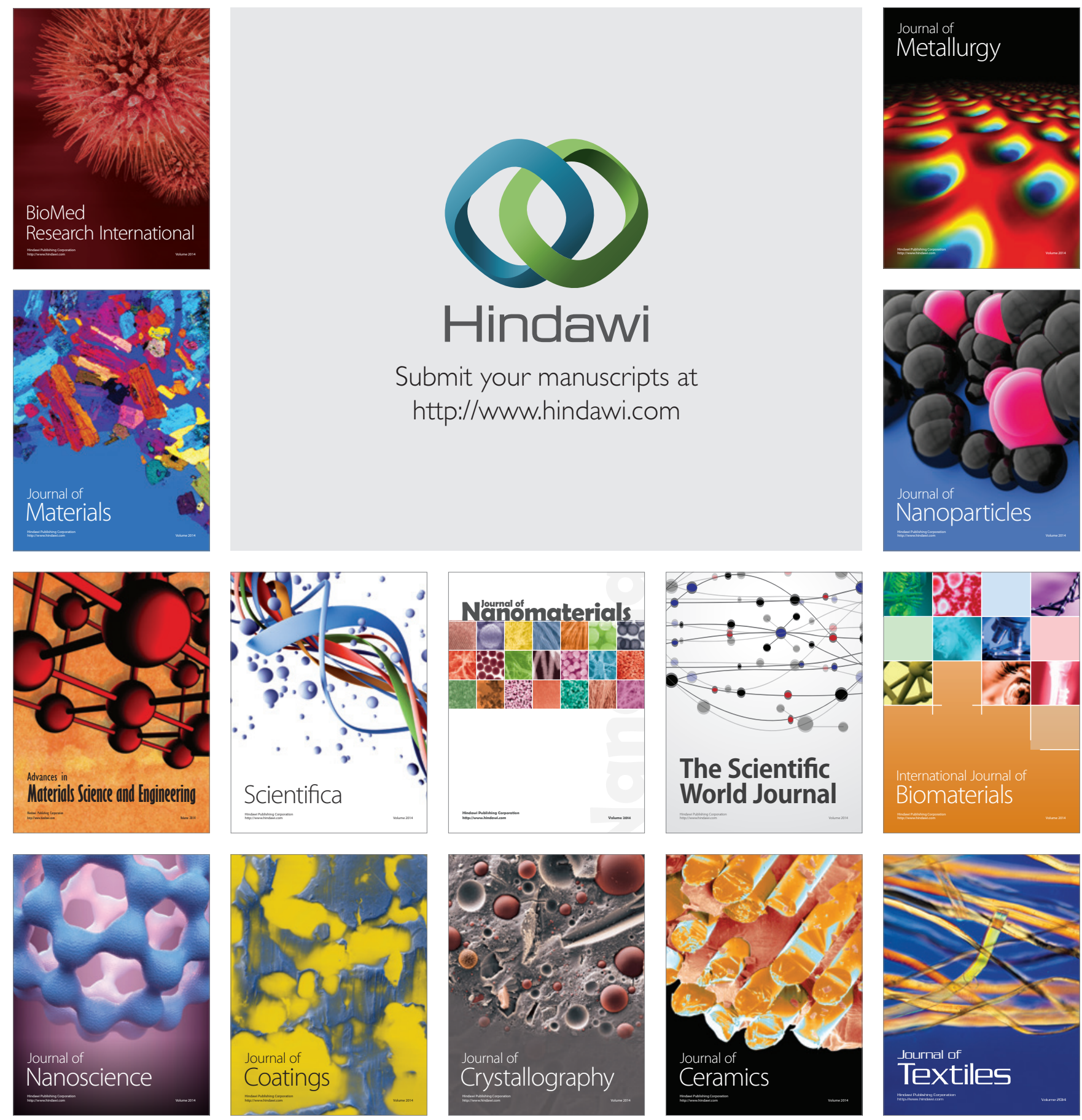